\title{
Influence of Aspect Ratio on the Performance Characteristics of Plain Journal Bearing Lubricating With Non-Newtonian Lubricant
}

\author{
Pravez Khan, Anil Dhanola, H.C. Garg, Aman Khatkar
}

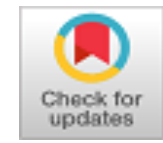

\begin{abstract}
This article presents the static performance characteristics of a plain journal bearing with non-Newtonian lubricant (power law) at different aspect ratio. Finite difference approach is employed to solve the modified Reynold equation. Hydrodynamic regime is assumed to be isothermal. The fluid film pressure is established using modified Reynold equation and Reynold boundary condition through iteratively. Thus the obtain pressure is used to find-out the performance characteristics for instance load carrying capacity, attitude angle, friction force and side leakage. Three aspect ratios are assumed $0.5,1$ and 1.5 for the present study. The effect of different aspect ratios on performance characteristics at different power law index $(0.9,1$ and 1.1) has been presented.
\end{abstract}

Index Terms: Journal bearing, Aspect ratio, Power law model, non-Newtonian lubricant.

\section{INTRODUCTION}

Journal bearings are employed in large scale in many high rotating machineries such as compressor, generator, steam turbine, internal combustion engine etc. A typical journal bearing equipped with a shaft and a bush (in which shaft rotates and bush remains immobile). In hydrodynamic lubrication, hydrodynamic pressure is induced due to relative motion between journal and bearing surface. This pressure solely responsible to carried out the applied load [1]. There are various characteristics like surface roughness, fluid inertia, viscosity of lubricant, geometry and aspect ratio which affects the performance parameters of journal bearing. Aspect ratio $(\mathrm{L} / \mathrm{D})$ is one of the critical specification that can affect the performance of journal bearing. Influence of various aspect ratios on performance characteristics have been investigated by [2-4]. They observed that aspect ratio affect the stability of journal bearing at some extent. Sufficient amount of work have been done on performance characteristics taking into account of

Revised Manuscript Received on October 30, 2019.

* Correspondence Author

Pravez Khan*, Department of Mechanical Engineering, Guru Jambheswar University of Science and Technology, Hisar, Haryana, India.

Anil Dhanola, Department of Mechanical Engineering, Guru Jambheswar University of Science and Technology, Hisar, Haryana, India.

H.C. Garg, Department of Mechanical Engineering, Guru Jambheswar University of Science and Technology, Hisar, Haryana, India.

Aman Khatkar, Department of Mechanical Engineering, Shiv Nadar University, Greater Noida, Uttar Pradesh, India.

(C) The Authors. Published by Blue Eyes Intelligence Engineering and Sciences Publication (BEIESP). This is an open access article under the CC BY-NC-ND license (http://creativecommons.org/licenses/by-nc-nd/4.0/) the effect of aspect ratio [5-11]. Das et al. [5] presented the performance of hydrodynamic journal bearing operated with micro-polar fluids at various aspect ratio and eccentricity ratio. A first order perturbation technique was adopted to examine the fluid film pressure, fluid film thickness and dynamic coefficients. Bhushan et al. [6] presented the behavior of four-lobe pressure dam bearing at different aspect ratio (L/D) ranging from 0.75 to 1.5 . The outcomes reveal that stability of 4-lobe pressure dam bearing increases with decreasing aspect ratio ratios. Batra et al. [7] investigated the static and dynamic behavior of three- lobe pressure dam bearing using finite element approach. They concluded that the stability of this type of journal bearing highly depends upon the L/D ratio and the stability decreases with increasing L/D ratios. Sharma and Krishna [8] studied the performance parameters 2-lobe pressure dam bearing using micro-polar fluids at different L/D ratios (1.6, 2.0 and 2.4). They concluded that the stability of bearing is increases with decreasing aspect ratio. Saikia and Kalita [9] investigated the performance parameters of porous journal bearing under turbulent regime using finite difference scheme. They noted that the load carrying capacity and attitude angle rises with increasing aspect ratio while friction coefficient decreases. Sharma and Awasthi [10] studied the dynamic and static performance of a plain journal bearing at various aspect ratio $(0.5,1$ and 1.5$)$. The results revealed that the fluid film thickness, friction factor and damping coefficient increases with increasing aspect ratio also the stability deteriorates with increasing aspect ratio. Sharma and Awasthi [11] further studied the performance of journal bearing under wear condition at different aspect ratio. They observed that influence of wear on performance parameters was more dominant at lower L/D ratios. Available literature shows that the performance parameters of plain journal bearing lubricating with non-Newtonian fluid at different aspect ratio is still not been investigated. Thus, this study based on the performance parameters of plain journal bearing with non-Newtonian fluid at different aspect ratio and at different power law index.

\section{ANALYSIS}

The modified Reynold equation for an incompressible and non-Newtonian fluids a plain journal bearing system in given in dimensionless form as:

$$
\frac{\partial}{\partial \theta}\left[\bar{h}^{\mathrm{a}} \overline{F_{a}} \frac{\partial \bar{p}}{\partial \theta}\right]+\frac{1}{4 \lambda^{2}} \frac{\partial}{\partial \bar{y}}\left[\bar{h}^{\mathrm{a}} \overline{F_{a}} \frac{\partial \bar{p}}{\partial \bar{y}}\right]=\frac{\partial}{\partial \theta}\left[\bar{h}\left(1-\frac{\overline{F_{1}}}{\overline{F_{0}}}\right)\right]
$$


where, $\quad \bar{F}_{0}=\int_{0}^{1} \frac{1}{\bar{\mu}} d \bar{z}, \bar{F}_{1}=\int_{0}^{1} \frac{\bar{z}}{\bar{\mu}} d \bar{z}_{v} \quad \bar{F}_{2}=\int_{0}^{1} \frac{\bar{z}^{2}}{\bar{\mu}} d \bar{z}_{3} \bar{F}_{a}=\bar{F}_{2}-\frac{\bar{F}_{1}^{2}}{\bar{F}_{0}}$

Figure 1 presents graphic diagram of plain journal bearing and its coordinate.

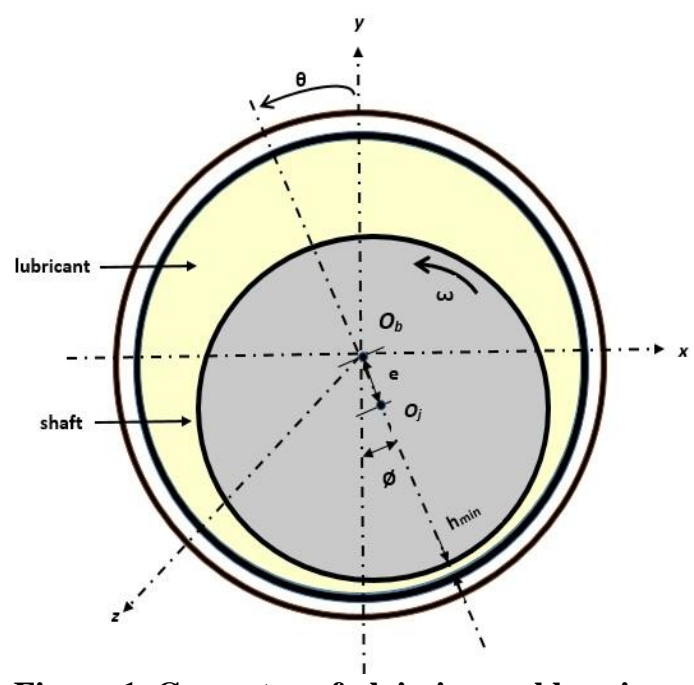

Figure 1. Geometry of plain journal bearing

\section{A. Boundary Conditions}

Following pressure boundary conditions are assumed for the solution:

$$
\begin{aligned}
& \bar{p}=0 \text { at } \bar{z}=0,1 \\
& \bar{p}=0 \text { at } \theta=0 \\
& \bar{p}=\frac{\partial \bar{p}}{\partial \theta}=0 \text { at } \theta=\theta_{c} \\
& \bar{p}=0 \text { at } \theta_{c} \leq \theta \leq 2 \pi
\end{aligned}
$$

\section{B. Power Law Model}

Power law model don't shows linear behavior between shear stress and shear strain rate and it is presented in dimensionless form as:

$$
\begin{aligned}
& \bar{\mu}=\bar{m}^{n-1} \\
& \text { where, } \bar{m}=\left(\frac{U}{c}\right)^{n-1}
\end{aligned}
$$

Where for the value of $n=1$, lubricant is Newtonian, $n<1$ lubricant is pseudoplastic and $\mathrm{n}>1$ lubricant is dilatant.

\section{Fluid Film Thickness}

The fluid film thickness at any angle in non-dimensional form is presented by:

$$
\bar{h}=1+\varepsilon \cos \theta
$$

\section{STEADY STATE PERFORMANCE CHARACTERISTICS}

\section{A. Load Carrying Capacity and Attitude Angle}

The load components in dimensionless form are:

$$
\begin{aligned}
& \overline{W_{r}}=-\int_{0}^{1} \int_{0}^{\theta_{c}} \bar{p} \cos \theta d \theta d \bar{y} \\
& \overline{W_{\theta}}=\int_{0}^{1} \int_{0}^{\theta_{c}} \bar{p} \sin \theta d \theta d \bar{y}
\end{aligned}
$$

Therefore, the total load carrying capacity in dimensionless form is given as:

$$
\bar{W}=\sqrt{\left(\overline{W_{r}}\right)^{2}+\overline{\left(W_{\theta}\right)^{2}}}
$$

The attitude angle is given by:

$$
\emptyset=\tan ^{-1}\left(\frac{W_{\theta}}{\overline{W_{r}}}\right)
$$

\section{B. Friction Factor}

Friction force acting on the journal bearing using non-Newtonian lubricant can be calculated using below expression. The non-dimensional form of friction force is given as:

$$
\bar{F}=\int_{0}^{1} \int_{0}^{2 \pi}\left(\bar{h} \frac{\partial \bar{p}}{\partial \theta}\left[1-\frac{\bar{F}_{1}}{\bar{F}_{0}}\right]+\frac{1}{\bar{F}_{0} \bar{h}}\right) d \theta d \bar{y}
$$

So, that the coefficient of friction can be calculated as it is the ratio of friction force and the fluid film force and can be represented as:

$\overline{C_{f}}=\frac{\bar{F}}{\bar{W}}$

\section{SOLUTION PROCEDURE}

The modified non-dimensional Reynold equation (10) is determined numerically by finite element approach. The film domain is splitted into 100 intervals along the circumferential direction and 16 intervals in axial direction for the study purpose. MATLAB software is used to develop the computational code. An Iterative procedure was followed by using a successive over-relaxation method to improve the convergence rate is employed. The iteration is executed till the convergence criteria is not achieved. The performance parameters for example load carrying capacity, attitude angle and friction coefficient are then solved at different $\mathrm{L} / \mathrm{D}$ ratio $(0.5,1$ and 1.5$)$ with taking power law index $(n=0.9,1$ and 1.1).

\section{RESULTS AND DISCUSSION}

This category presents the performance parameters for instance load carrying capacity, attitude angle and coefficient of friction of a plain journal bearing using non-Newtonian lubricant $(\mathrm{n}=0.9)$ at different $\mathrm{L} / \mathrm{D}$ ratio are presented and discussed. Technical data used in the present investigation is depicted in table 1.

Table 1. Technical data

\begin{tabular}{lcc}
\hline 1 & Bearing aspect ratio $(\lambda)$ & $0.5,1.0,1.5$ \\
2 & Lubricant model & Power law \\
3 & Power law index $(\mathrm{n})$ & $0.9,1,1.1$ \\
4 & Clearance ratio $(\bar{c})$ & 0.002 \\
5 & Speed $(\mathrm{N})$ & $1000 \mathrm{rpm}$ \\
6 & Number of elements & $100 \mathrm{x} 16$ \\
7 & Eccentricity ratio $(\varepsilon)$ & 0.6 \\
\hline
\end{tabular}

The influence of different L/D ratio (0.5, 1 and 1.5) on the performance parameters of a plain journal bearing using non-Newtonian lubricant is shown in figures 2 to 6 . Developed code in MATLAB was validate and compared with the previous results of [12] and it is found that the current results are to be fine agreement with the already published results.

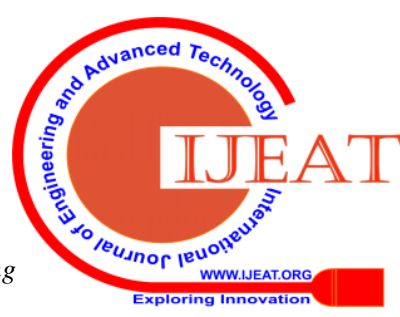


It is noted from the figure 2 that the

dimensionless pressure distribution increases with increasing the $\mathrm{L} / \mathrm{D}$ ratios and also this trend is found same at every power law index value (n). Highest pressure distribution is found for the case of dilatant fluid $(n=1.1)$ at $\mathrm{L} / \mathrm{D}=1.5$. Figure 3 depicts the effect of different $\mathrm{L} / \mathrm{D}$ ratio with non-dimensional maximum pressure $\left(\bar{p}_{\max }\right)$ at various value of $n$. Figure clearly reveals that the $\bar{p}_{\max }$ increases with an increase of aspect ratio. It is also noted that $\bar{p}_{\max }$ increases with an increase of $\mathrm{n}$ at each value of $\mathrm{L} / \mathrm{D}$ ratio. $\bar{p}_{\max }$ is observed maximum for dilatant fluid at $\mathrm{L} / \mathrm{D}=1.5$.

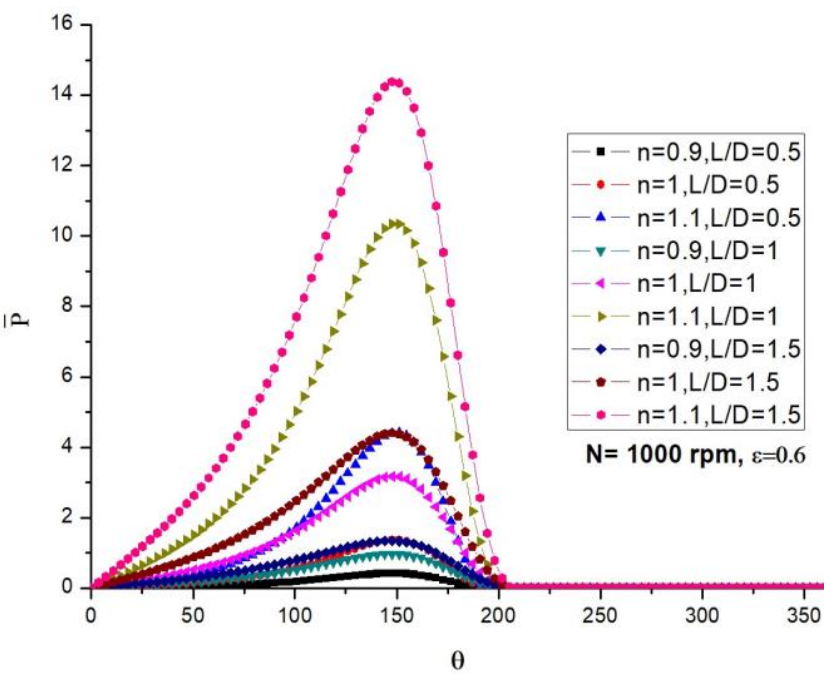

Figure 2: Circumferential Pressure Distribution At Different N And L/D Ratio

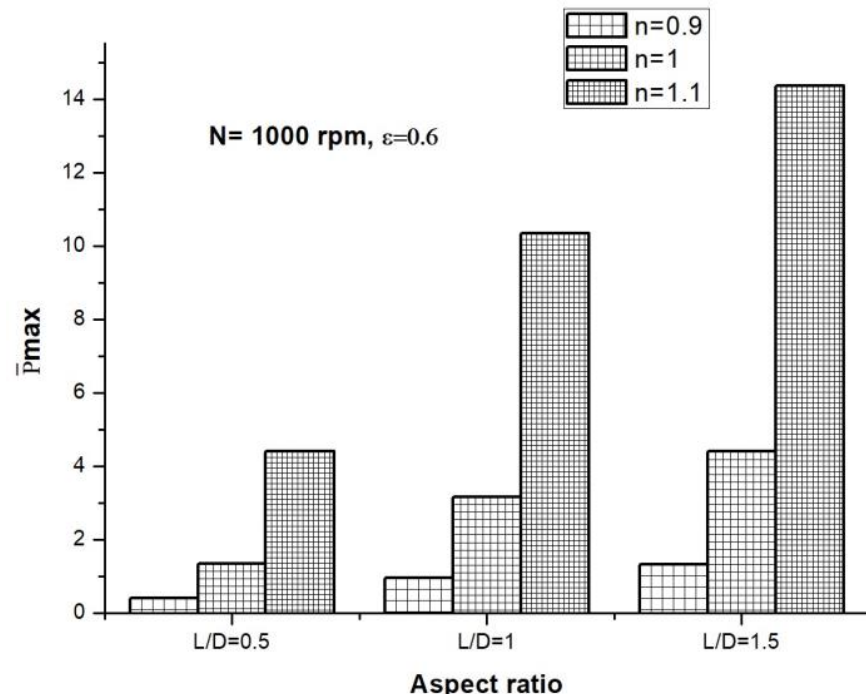

Figure 3: Variation in $\bar{p}_{\max }$ with aspect ratio at different n

Figure 4 shows the influence of different aspect ratio with dimensionless load carrying capacity $(\bar{W})$ at various value of n. Figure reveals that the $\bar{W}$ increases with an increase of aspect ratio. It is also noted that $\bar{W}$ increases with an increase of $\mathrm{n}$ at each value of $\mathrm{L} / \mathrm{D}$ ratio. Highest $\bar{W}$ is found at $n=1.1$ with $\mathrm{L} / \mathrm{D}=1.5$.

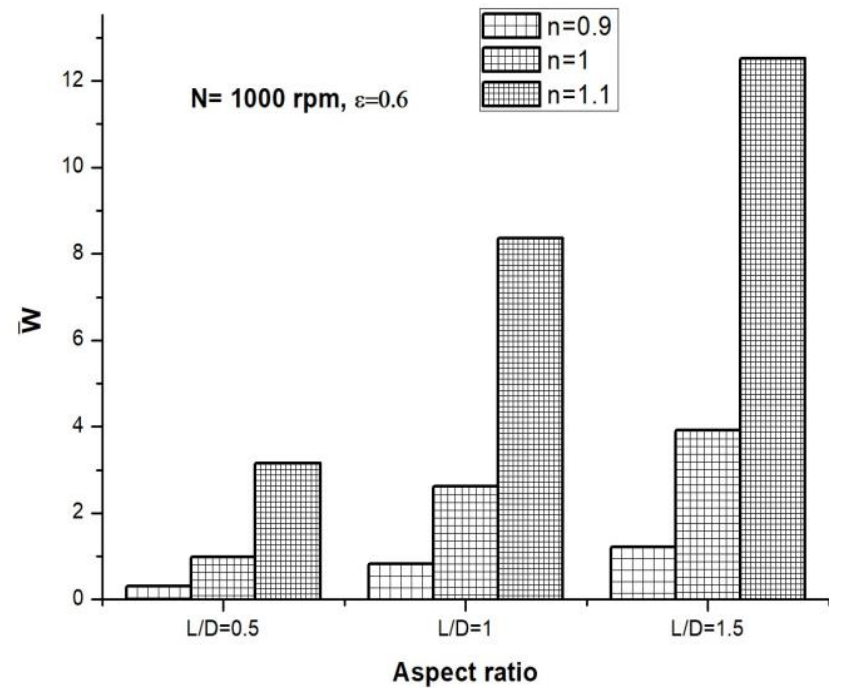

Figure 4: Variation in $\bar{W}$ with aspect ratio at different n

Figure 5 shows the influence of different L/D ratio with attitude angle $(\phi)$ at various value of $n$. Figure presents that the $\phi$ increases with increasing the aspect ratio. But it is also seen that $\phi$ decreases with an increase of $n$ at each value of $\mathrm{L} / \mathrm{D}$ ratio. Highest $\phi$ is found for pseudoplastic lubricant $(\mathrm{n}=0.9)$ at $\mathrm{L} / \mathrm{D}=1.5$.

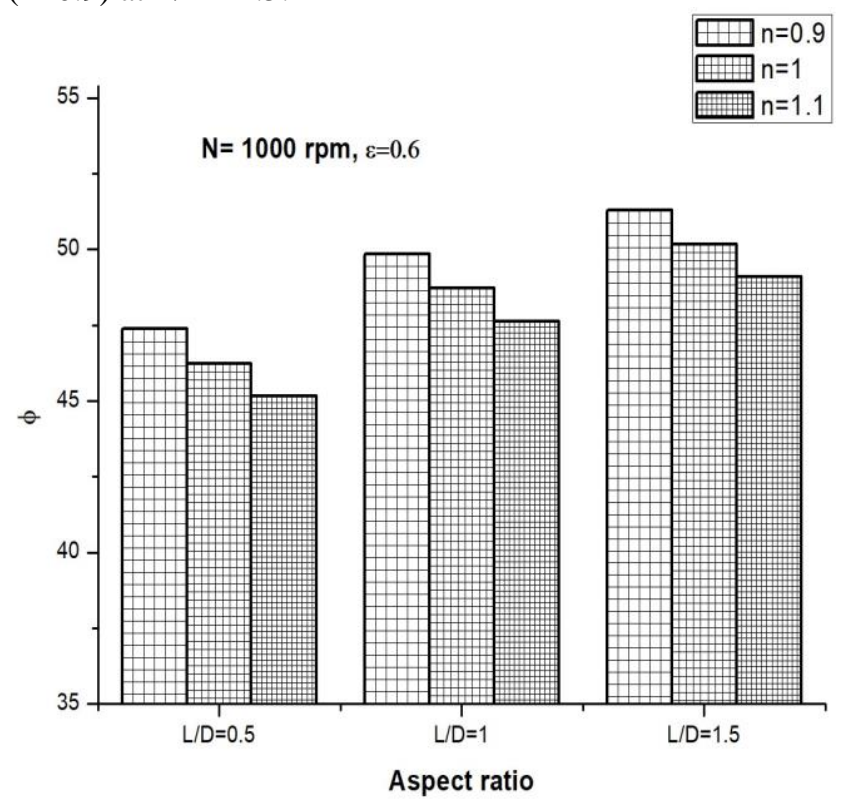

Figure 5: Variation in $\phi$ with aspect ratio at different $n$

Figure 6 depicts the effect of different aspect ratio with dimensionless friction coefficient $\left(\bar{C}_{f}\right)$ at various value of $n$. Figure presents that the $\bar{C}_{f}$ decreases with increasing the $\mathrm{L} / \mathrm{D}$ ratio. But it is also seen from the figure that $\bar{C}_{f}$ decreases slightly with an increase of $n$ at each value of $L / D$ ratio. Maximum $\bar{C}_{f}$ is noted for pseudoplastic lubricant $(\mathrm{n}=0.9)$ at $\mathrm{L} / \mathrm{D}=0.5$. 


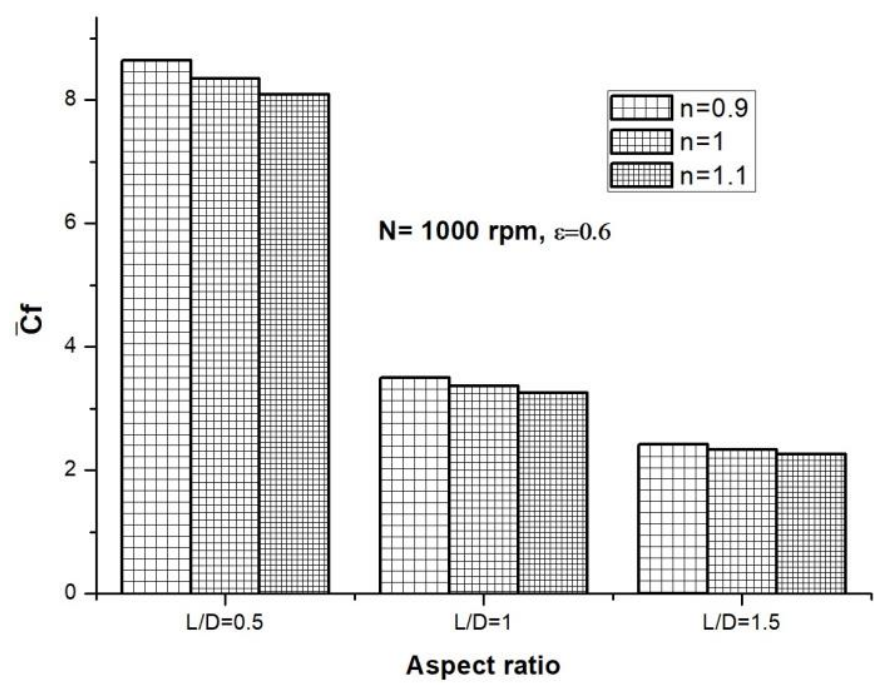

Figure 6: Variation in $\bar{C}_{f}$ with aspect ratio at different $\mathbf{n}$

\section{CONCLUSIONS}

1. It is observed from the above results that the performance characteristics affects with the variation of aspect ratio.

2. Dimensionless maximum pressure increases with increasing aspect ratio. Maximum pressure is observed maximum for dilatant fluid at $\mathrm{L} / \mathrm{D}=1.5$

3. Load carrying capacity increases with increasing aspect ratio. Maximum load carrying capacity is observed for dilatant fluid at $\mathrm{L} / \mathrm{D}=1.5$.

4. Attitude angle also increases with an increase of aspect ratio. Pseudoplastic lubricant has highest attitude angle at $\mathrm{L} / \mathrm{D}=1.5$.

5. Non-dimensional coefficient of friction decreases with an increasing the aspect ratio. Highest coefficient of friction is found maximum for pseudoplastic lubricant at $\mathrm{L} / \mathrm{D}=0.5$.

6. Performance characteristics also affect with power law index at different aspect ratio.

\section{REFERENCES}

1. S. Kasolang and M. A. Ahmada, "Preliminary study of Pressure Profile in Hydrodynamic Lubrication Journal Bearing”, Procedia Engineering, vol. 41, pp. $1743-1749,2012$

2. Y. Hori, "A theory of oil whip," Journal of Applied Mechanics, vol. 26, no. 2, pp. 189-198, 1959.

3. R. H. Badgley and J. F. Booker, "Turborotor instability: effects of initial Transients on plane motion," Journal of Lubrication Technology, vol. 91, no. 4, pp. 625-630, 1969.

4. S. B. Shenoy and R. Pai, "Steady state performance characteristics of a single pad externally adjustable fluid film bearing," Journal of Advanced Mechanical Design, Systems, and Manufacturing, vol. 2, no. 5, pp. 937-948, 2008.

5. S. Das , S.K. Guha and A. K. Chattopadhyay, "Linear stability analysis of hydrodynamic journal bearings under micropolar lubrication", Tribology International, vol.38,pp. 500-507, 2005.

6. G. Bhushan, S. S. Rattan, and N. P. Mehta, "Effect of L/D Ratio on the Performance of a Four-Lobe Pressure Dam Bearing", World Academy of Science, Engineering and Technology international journal of mechanical and mechatronics engineering, vol.1, No. 8, 2007.

7. N. K. Batra, Gian Bhushan and N. P. Mehta, "Effect of L/D Ratio on the Performance of an Inverted Three-lobe Pressure Dam Bearing", Journal of Engineering and Technology, vol. 1 Issue 2, 2011.

8. S. Sharma and C. M. Krishna, "Effect of $L / D$ Ratio on the Performance of Two-Lobe Pressure Dam Bearing: Micropolar Lubricated", Advances in Tribology, vol. 2015, Article ID 182713, 7 pages.

9. K. Saikia and K. Kalita, "Steady State Characteristics of Finite Hydrodynamic Porous Oil Journal Bearing Under Turbulent Regime”,
International Advanced Research Journal in Science, Engineering and Technology, vol. 2 issue 12, 2015.

10.S. Sharma and R. K. Awasthi, "Effect of aspect ratio on the performance and stability of Hydrodynamic Journal Bearings", International Journal of Advance Research and Innovation, vol. 4, Issue 1, pp. 96-105, 2016.

11.S. Sharma and R. K. Awasthi, "Effect of Aspect Ratio on the Performance of Hydrodynamic Journal Bearing Operating Under Wear", International Journal of Theoretical and Applied Mechanics, vol. 12, Number 3, pp. 497-522, 2017.

12.J. Jang , C. Chang, “Adiabatic Analysis of Finite Width Journal Bearings with Non-Newtonian Lubricants”, Wear, vol. 122, pp. 63-75, 1988.

\section{Nomenclature}

U tangential velocity of the journal, $\mathrm{m} / \mathrm{s}$

$\omega$ angular velocity of the journal ( $\omega=\mathrm{U} / \mathrm{R}), \mathrm{rad} / \mathrm{sec}$

$\mathrm{h}$ film thickness, $\mathrm{m}$

e eccentricity, $\mathrm{m}$

$\mathrm{O}_{\mathrm{b}}$ bearing centre

$\mathrm{O}_{\mathrm{j}}$ journal centre

$\mathrm{h}_{\text {min }}$ minimum fluid film thickness, $\mathrm{m}$

$\mu$ apparent viscosity, Pa-s

$\mu_{0}$ reference viscosity of the lubricant, Pa-s

$\mathrm{x}, \mathrm{y}, \mathrm{z}$ bearing coordinates, $\mathrm{x}$ measures along circumferential direction, $y$ measures along the radial direction, $\mathrm{z}$ measures along the axial direction, $\mathrm{m}$

$\theta$ angular coordinate, rad

$\mathrm{R}$ journal radius, $\mathrm{m}$

$\mathrm{D}$ journal diameter, $\mathrm{m}$

$\mathrm{L}$ bearing length, $\mathrm{m}$

c radial clearance, $\mathrm{m}$

$\theta_{c}$ cavitation angle, rad

$\mathrm{n}$ power law index

$\varepsilon$ eccentricity ratio

$\phi$ attitude angle, degree

p lubricant film pressure, $\mathrm{N} / \mathrm{m}^{2}$

Wload carrying capacity, $\mathrm{N}$

$\mathrm{W}_{\mathrm{x}}$ tangential component of load carrying capacity, $\mathrm{N}$

$\mathrm{W}_{\mathrm{r}}$ radial component of load carrying capacity, $\mathrm{N}$

$\mathrm{C}_{\mathrm{f}}$ coefficient of friction

$\mathrm{F}$ friction force, $\mathrm{N}$

Non- dimensional parameters

$\begin{array}{lcl}\theta=\frac{\mathrm{x}}{\mathrm{R}} & \overline{\mathrm{p}}=\frac{c^{2} \mathrm{p}}{\mu_{0} \omega \mathrm{R}^{2}} \quad \overline{W_{\theta}}=W_{\mathrm{s}} \frac{c^{2}}{\mu_{\theta} \omega \mathrm{R}^{2} L} \quad \overline{W_{p}}=W_{p} \frac{c^{2}}{\mu_{\theta} \omega \mathrm{R}^{2} L} \\ \bar{\mu}=\frac{\mu}{\mu_{0}} \quad \overline{\mathrm{z}}=\frac{\mathrm{z}}{\mathrm{h}} \quad \bar{\varepsilon}=\frac{\mathrm{e}}{\mathrm{c}} \quad \overline{\mathrm{h}}=\frac{h}{c} \quad \bar{F}=\frac{F c}{\mu_{0} \omega \mathrm{R}^{2} L} \\ \bar{m}=\left(\frac{U}{c}\right)^{n-1} \quad \bar{c}=\frac{\mathrm{R}}{\mathrm{c}}\end{array}$

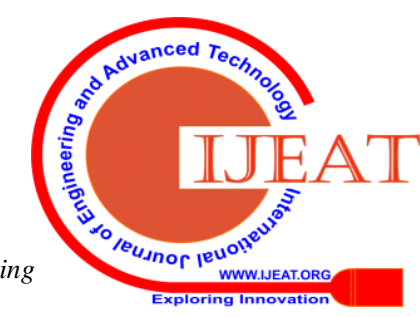



$\bar{W}=W \frac{\mu_{0} \omega \mathrm{R}^{a} L}{c^{2}}$
$\bar{y}=\frac{y}{L}$
$\lambda=\frac{\mathrm{L}}{\mathrm{D}}$
$\bar{C}_{f}=\frac{C_{f} R}{c}$

\section{AUTHORS PROFILE}

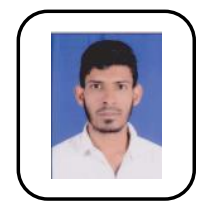

Pravez Khan, B.Tech. , Currently pursuing Master of Technology in Mechanical Engineering from Guru Jambheswar University of Science and Technology, Hisar, Haryana, India. Fields of interest includes: Fluid film lubrication and Tribology.

Email: pravezkhan0001@gmail.com

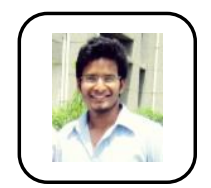

Anil Dhanola, M.Tech. , Currently pursuing Ph.D. (Full Time) in Mechanical Engineering from Guru Jambheswar University of Science and Technology, Hisar, Haryana, India. Fields of interest includes: Composite materials, Natural fiber reinforced materials and Tribology.

Email: anildhanola3698@gmail.com

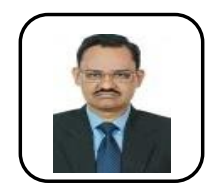

Prof. H.C. Garg, Ph.D., Working as a Professor in Mechanical Engineering at Guru Jambheswar University of Science and Technology, Hisar, Haryana, India. Fields of interest includes: Tribology, Machine design. Email:hcgarg@gmail.com

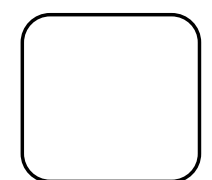

Aman Khatkar Currently pursuing Bachelor of Technology in Mechanical Engineering from Shiv Nadar University, Greater Noida, Uttar Pradesh, India.

Email: aman.khatkar@snu.edu.in 